\title{
El discurso y su relación con el límite exterior del lenguaje
}

\author{
THE DISCOURSE AND ITS RELATION TO THE OUTER LIMITS OF LANGUAGE
}

Mg. Daniel Paulos (dnlpaulos@hotmail.com) Facultad de Filosofía y Humanidades, Universidad Austral de Chile (Valdivia, Chile)

\begin{abstract}
The paper analyzes some of the problems involved in defining speech, with the aim of showing the epistemic choices involved in its implementation as a methodology or analysis technique. The difficulty of the concept of discourse is its bordering nature of language structures and contextual domains that shape utterances, which has led to different approaches: the contextualized utterances, institutions governing language formation of statements or sociohistorical systems that explain its regularity. Such uncertainty increases when registering the models on the set of concomitant concepts, from which derive various extensions of the discursive, basically the discourse as inner domain of ideology, and in which connection the subject form, or as a representation of social concepts in serving an ideological domain and a cognitive domain of prediscursive character.
\end{abstract}

Key words: discourse, utterance, text, subject, ideology.

\section{Resumen}

El trabajo analiza algunos de los problemas implicados en la definición de discurso, con el objetivo de mostrar las opciones epistémicas implicadas en su aplicación como metodología o técnica de análisis. La dificultad del concepto de discurso radica en su carácter de frontera entre las estructuras de lenguaje y los dominios contextuales que dan forma a los enunciados, lo que ha derivado en enfoques cuyo objeto es distinto: los enunciados contextualizados, las instituciones de lenguaje que regulan la formación de los enunciados o los sistemas sociohistóricos que explican su regularidad. Tal indeterminación aumenta al inscribir los modelos en el conjunto de conceptos concomitantes al discurso, de donde derivan distintas extensiones de lo discursivo, básicamente, el discurso como dominio interior a la ideología, y en cuya conexión se forma el sujeto, o en cuanto representación de lo social en que actúa un dominio ideológico y un dominio cognitivo, de carácter prediscursivo.

Palabras clave: discurso, enunciado, texto, sujeto, poder, ideología.

\section{Introducción}

Uno de los problemas centrales que debe abordar una conceptualización del discurso es la determinación de su dominio propio, su lugar específico entre las estructuras de la lengua y las circunstancias situacionales y sociohistóricas que determinan las formas y sentidos efectivos de lo dicho. Aunque es usual que la literatura omita o simplifique este problema, una lectura atenta de los autores fundacionales del 
campo muestra que es un asunto definitorio en la configuración de los distintos enfoques y de sus respectivas operacionalizaciones como método o técnica de análisis.

En el presente trabajo nos proponemos mostrar algunos de los principales aspectos de este debate, resaltando las opciones epistémicas implicadas y los consecuentes riesgos de una integración descuidada de autores y conceptos.

Este mismo carácter de frontera que caracteriza al discurso explica la vastedad del problema en cuestión, por cuanto toda definición debe conectar conceptos que remontan a tradiciones y campos de estudios variados (sujeto, ideología, texto, enunciación, situación de comunicación, entre otros). En esta complejidad, hemos optado por centrarnos en algunos autores fundamentales en la constitución de la disciplina que, durante los años setenta, asume el nombre de análisis del discurso, omitiendo generalmente las conexiones del problema con la hermenéutica, la pragmática filosófica, el posestructuralismo, la Escuela de Frankfurt y, de alguna manera, el devenir de todas las humanidades en el siglo XX. No obstante, han sido necesarios algunos vínculos excepcionales, así como abordar con algún detalle la obra de Michel Foucault.

Por otra parte, no hemos considerado la usual distinción entre escuelas o corrientes, ni hemos otorgado a la historia de la disciplina un lugar central. El criterio ha sido deshilvanar ejes temáticos transversales en los diversos enfoques. Esta estrategia ha impuesto cierta recurrencia de algunos planteamientos, que hemos intentado atenuar.

\section{El territorio del discurso}

La abundante literatura en análisis del discurso ha configurado una historia de la disciplina caracterizada por ciertos tópicos, dos de los cuales nos servirán para formular el problema que abordaremos.

El primero afirma un origen indirecto que, aunque podría remontarse a la tradición de estudios sobre el lenguaje iniciada en la antigüedad grecolatina, es establecido en la fundación saussureana de la semiótica, pero, significativamente, en términos de controversia: Saussure establece una dicotomía entre la lengua (el sistema) y el habla (la realización individual), para luego sostener que el pensamiento científico solo puede aplicarse al primer dominio, siendo el segundo impensable por cuanto "no es homogéneo" (Saussure 1991:47).

Como ha sido frecuentemente descrito, diversas disciplinas y tradiciones avanzaron durante el siglo XX en el intento contrario, comprender el uso efectivo del lenguaje, proceso que afectó los enfoques tradicionales tanto de la lingüística como de las tradiciones filosóficas interesadas en la significación: el análisis formal de las oraciones y la pregunta por sus valores de verdad cede lugar al estudio de los usos y sentidos que los hablantes reales otorgan al lenguaje en situaciones reales; de esta manera, bajo un recorrido histórico complejo, surgen las figuras centrales del campo: enunciado, discurso, texto, para consignar tales unidades de comunicación.

Estas tres nociones, sin embargo, no poseen fronteras claras. El segundo tópico consiste en recalcar que su uso cambiante es efecto no solo de la complejidad inherente a toda disciplina, sino que del carácter difuso de sus referentes: ahí donde "lengua" alude a un sistema de signos y se asume que el uso de las lenguas está determinado por factores sociales e históricos de diverso tipo, las instancias del discurso, del 
enunciado o del texto, buscan asir la conexión de esos dos ámbitos sin que haya acuerdo en la amplitud precisa del dominio resultante.

De acuerdo con este relato, cuando el nuevo objeto se configura definitivamente a fines de los años sesenta, deja ver que su funcionamiento "no es integralmente lingüístico" (Pêcheux 1978:43), irreductibilidad que, en todo caso, ya había sido advertida por Benveniste al observar que entre el dominio de los signos, caracterizado por la remisión autorreferencial de las unidades al interior del sistema, y el dominio del discurso (en el sentido de enunciación de un mensaje), caracterizado por la apertura de ese sistema hacia una situación y unos referentes que explican la comunicación, existe "un hiato", por cuanto el mensaje "no es una suma de signos" (Benveniste 2011:67), sino que un sentido completo en que han actuado determinantes heterogéneas. En adelante, sin excepción, la literatura insistirá en que, ya sea que nos refiramos a un complejo discurso literario o a una simple conversación cotidiana, la significación de una trama de enunciados solo es explicable en su conexión con fuerzas socio históricas de gran alcance, la red de discursos en que participa, las tipologías genéricas en que se inscribe y un vasto conjunto de variables situacionales y subjetivas que tejen sus detalles. Consecuentemente, el análisis se abocará a conectar huellas textuales y variables contextuales, en un ejercicio cuya dispersión es reconocida y que sintomáticamente se manifiesta en la abundancia de literatura que intenta sistematizarla.

La noción de discurso, como de sus concomitantes enunciado y texto, no obstante tales intentos, mantiene su estatuto difuso, un territorio "entre" el lenguaje y el contexto que lo determina, pensable desde uno y otro extremo, pero irreductible a ambos.

Tal como veremos a continuación, la disposición de los conceptos en esa zona limítrofe y los acentos relativos entre ellos a veces los plegará (por ejemplo, texto es igual a discurso) y en otras los desplegará (por ejemplo, el discurso es exterior a los enunciados), asunto terminológico que es huella de distinciones conceptuales de base y que supone, entre otros aspectos, recortar el campo de estudios para hacerlo más cercano al lenguaje o ampliarlo hasta abarcar toda su complejidad.

El acercamiento que realizaremos para observar esa trama consiste, primero, en extraer tres ejes temáticos en torno a los cuales los distintos modelos se han posicionado, generando definiciones distintas de discurso: el eje de la dependencia de este con las materializaciones verbales que lo expresan, aquel que lo delimita en relación con las redes en que se forma y el eje de la definición de sujeto pertinente a su estudio. Efectuado ese análisis se observarán las principales inscripciones de los conceptos de ideología y poder en los modelos, por cuanto es fundamentalmente a través de estos dominios que cada enfoque se ha inscrito en los debates más generales referidos a la relación entre el lenguaje y lo real, mostrando así sus distintos trasfondos filosóficos.

\section{Discurso como texto o sistema}

El primer asunto se dispone a partir de una distinción de base: o bien se observa el discurso desde las materializaciones efectivas de la comunicación (una carta, una conversación, una novela) o desde los dominios contextuales que determinan esas producciones.

Así, desde un enfoque pragmático y socio cognitivo, Van Dijk entiende el discurso como "cualquier forma de uso del lenguaje" (2012:179): una emisión delimitada material, espacial y temporalmente a partir del acto intencional (pragmático) de un sujeto hablante, individual o colectivo, perspectiva que implica su sinonimia con texto o con interacciones habladas, reservando la noción de enunciado para el "objeto 
expresado" (1983:79) o componente semántico de un acto de habla, un segmento del discurso caracterizado por su fuerza intencional (ilocutiva).

Otros autores, en cambio, conciben el discurso como las reglas socio históricas que regulan el habla, permitiendo que la ilimitada posibilidad combinatoria, característica de los sistemas de lenguaje, adquiera regularidad y con ello comunicabilidad. En palabras de Charaudeau "un lugar de restricciones" (2004:29) o un "filtro complejo" en palabras de Kerbrat-Orecchioni (1997:38); perspectiva que ha abierto dos orientaciones a la investigación, usualmente concatenadas. Primero, observar las instituciones que constituyen la frontera exterior del lenguaje, los tipos y géneros que inscriben los enunciados en escenarios sociales específicos, dándoles forma, propósito y usos reconocibles; codificaciones "que, según toda evidencia no corresponden a una teorización estrictamente lingüística" (Adam y Heidmann 2004:62). $Y$, luego, hacia la inscripción de esa exterioridad en los enunciados, un "proceso subyacente por el cual lo expresado es atribuible a un yo que apela a un tú" (Filinich 2012:20), cuyo análisis se encierra bajo el concepto de enunciación y apela al conjunto de marcas explícitas e implícitas de esa dialogicidad, cuya característica central es la formación de una representación verbal de la situación extra lingüística que explica el acto de habla: en definitiva, marcas de tiempo y de lugar, de las relaciones del enunciado con otros, de las imágenes que los enunciadores adoptan para sí o de las atribuciones que otorgan a los referentes de los que hablan, configurando un universo discursivo yuxtapuesto con los acontecimientos exteriores al habla.

En tal contexto, en que el enunciado constituye el producto visible del acto de la enunciación, la noción de texto puede pensarse como equivalente del primero, si lo que se acentúa es el rasgo de "unidad de comunicación completa que forma parte de un género discursivo determinado" (Maingueneau 2009:46), tal como lo define Bajtín; u otorgarle un valor distintivo -no excluyente de lo anterior-si lo que se acentúa es el carácter de materialidad del texto, es decir, de "producciones verbales orales o escritas que están estructuradas de manera de durar, de ser repetidas, de circular lejos de su contexto original" (Maingueneau 2009:47), y que por ello poseen el atributo semiótico de la coherencia entre secuencias que pueden sin problema ser llamadas enunciados elementales.

Por último, bajo un tercer enfoque, el discurso es pensado como una sistematicidad socio histórica amplia en que confluyen prácticas discursivas y no discursivas, sujetos, instituciones sociales y contingencias, regulando la formación e interpretación de los enunciados; el discurso excede aquí por completo el lenguaje y sus materializaciones textuales son pensadas ya no como formas que portan un sentido, sino como puntos en una red; las nociones de discurso "como el fluir del conocimiento - y de todo el conocimiento societal acumulado - a lo largo de toda la historia", formulada por Jäger (2003:63), o como aspecto semiótico "en la representación y en la autorrepresentación de las prácticas sociales" propuesta por Fairclough (2003:182), son ejemplos de ello.

Esta tercera perspectiva se manifiesta como continuidad crítica de la noción de discurso planteada por Foucault en su Arqueología del Saber: "conjunto de los enunciados que dependen de un mismo sistema de formación" (2003:181), sistema que es a su vez concomitante con las prácticas implicadas en su formación: "reglas anónimas, históricas, siempre determinadas en el tiempo y el espacio que han definido en una época dada, y para un área social, económica, geográfica o lingüística dada, las condiciones de ejercicio de la función enunciativa" (2003:198).

Consideramos que esta definición tiene un precursor en Ser y Tiempo de Heidegger. En el contexto de su definición de sentido como "aquello en lo que se mueve la comprensibilidad de algo" (2005:175), el 
discurso es entendido como la "articulación de la comprensibilidad" (2005:184) que manifiesta ese sentido en la formación de los enunciados, por lo tanto, el discurso es preformado y su comunicación no puede entenderse como diálogo entre interioridades de sujetos, sino que efecto del coestar ya pre comprendido en-el-mundo, de la historicidad del Dasein. Aunque la influencia de Heidegger en Foucault ha sido ampliamente estudiada, curiosamente no ha sido desarrollada al interior de los estudios del discurso.

\section{Discurso, sujeto y dialogicidad}

El problema de la relación entre lo discursivo y sus manifestaciones verbales tiene directa relación con las definiciones clásicas de autor y texto, de donde resulta una paradoja.

El análisis de discurso, como hemos observado, nace cuando los estudios sobre el lenguaje dirigen la mirada hacia las manifestaciones verbales efectivas de los hablantes y, por ello, la figura del texto pudiera imaginarse central en cualquier enfoque, ya sea si se lo separa o no del discurso. Pero desde sus inicios la teoría ha puesto en cuestión su unidad y preponderancia como fuente de sentido y ello en directa relación con la problematización de la figura, aparentemente evidente, de su autor, un sujeto que ha producido intencional y autónomamente ese enunciado o red de enunciados.

La discusión inicia con la obra de Bajtín, según el cual "todo enunciado es un eslabón en la cadena, muy complejamente organizada, de otros enunciados" (Bajtín 2008:255), por las temáticas que aborda, pero principalmente porque en su interior aparecen voces distintas ("ajenas"), como huellas de esa dialogicidad constitutiva. El recorrido posterior de esta premisa resulta en enfoques diversos.

Por una parte, asumir la nociones derivadas de intertextualidad o transtextualidad y sus correlatos es actualmente común en la investigación y puede convivir con las unidades del texto y del sujeto como autor, así, Van Dijk remite el problema a los conocimientos, creencias y esquemas socio cognitivos que forman parte del mundo de ese productor, toda vez que ello puede manifestarse en vínculos de un texto en otro, en definitiva, el problema de la dialogicidad es reducido a un recurso, entre otros, que "puede ser una condición importante para la significación y la adecuación del discurso" (2012:44), como efecto de trasladar a la cognición los aspectos definitorios de la teoría.

Una opción muy distinta toma Ducrot, radicalizando los planteamientos de Bajtín, al proponer que la multiplicidad de hablantes o voces alcanza el interior de los enunciados elementales de un texto, cuestionando con ello que pueda asignarse a un sujeto empírico la responsabilidad de su enunciación: la dialogicidad (polifonía) es postulada como principio estructurador del discurso y se traza una frontera entre el hablante real que profiere un enunciado, el locutor que asume la responsabilidad de su enunciación y los enunciadores particulares que eventualmente toman la responsabilidad de segmentos específicos. Incluso en el caso de enunciados asignables a una sola voz (locutor), Ducrot sostiene que "ya en este nivel abandonamos el terreno de la producción empírica del enunciado, ya que estamos frente a un ser discursivo, interno al sentido" (1984:261).

Este enfoque, que ya hemos aludido como característico de la teoría de la enunciación, mantiene, sin embargo, la figura del texto como objeto de su análisis, al mismo tiempo que la figura del sujeto autor es llevada fuera de la investigación.

Ambos conceptos son problematizados, en cambio, por Foucault, quien sostiene que uno y otro no deben ser pensados como exteriores a las formaciones discursivas. Todo texto (y específicamente su forma 
"libro") así como la figura del autor constituyen prácticas enunciativas determinadas: todo texto "está envuelto en un sistema de citas de otros libros, de otros textos, de otras frases, como un nudo en una red" (2003:37), y el autor constituye un "principio de agrupación del discurso, como unidad y origen de sus significaciones, como foco de su coherencia" (2012:29), así, el autor es una regla de formación de textos y libros, uno de cuyos efectos es ocultar la anterioridad de los enunciados al atribuirlos a la conciencia de un sujeto que se confunde con el hablante que profiere o escribe.

En términos metodológicos, el acento en los enunciados fragmentarios antes que en los textos y en sus autores se expresa, por ejemplo, en los modelos de Jäger, quien prescinde del texto mediante una estrategia que dirige su atención a la red de enmarañamientos de hilos discursivos temáticos, conectados entre sí a través de enunciados que cruzan los textos; o de Pêcheux, quien sostiene que "la producción del sentido es estrictamente indisociable de la relación de paráfrasis entre secuencias tales que la familia parafrástica de estas secuencias constituye lo que se podría llamar la matriz del sentido" (1978:237), esto es, que las remisiones entre enunciados al interior de las redes de textos vinculadas a partir de un eje temático, anteceden la aparente unidad de sentido de cada manifestación: cada enunciado solo es explicable a partir de la cadena de que forma parte.

\section{Los sujetos históricos y los enunciados}

La tesis del sujeto como construcción discursiva supone, aunque se la acepte como principio metodológico, un inconveniente sustantivo: deja intacta la pregunta por las interfaces entre los sujetos históricos y sus enunciados y, toda vez que el análisis del discurso nace como un intento por comprender la constitución social del habla, ha sido esta una cuestión irrenunciable de su programa.

En tal contexto, sin embargo, la alternativa propuesta por Ducrot, basada en los trabajos de Benveniste, quien sostiene el carácter lingüístico de la subjetividad, por cuanto "es en y por el lenguaje como el hombre se constituye como sujeto; porque el solo lenguaje funda en realidad, en su realidad que es la del ser, el concepto de "ego»" (Benveniste 2011:180), no debe ser entendida como una renuncia sino que como respuesta del problema; aparente contradicción que se resuelve al inscribir estos debates en el escenario más amplio que, durante el siglo XX, constituyó el llamado giro lingüístico de la filosofía: en términos muy generales, la sospecha de que lo real no se constituye mediante la representación de los objetos por una conciencia subjetiva cognoscente, sino que a través de las relaciones autorreferenciales entre los enunciados.

De este modo, sostener que el estudio del discurso debe desarrollarse sin referencias al sujeto extra lingüístico resulta de concebir que es en los enunciados donde este adquiere su existencia histórica; y afirmar, con Foucault, el carácter discursivo de las figuras del autor y del texto, no constituye sino un acercamiento yuxtapuesto al asunto: el individuo no es autor de lo que dice, sus palabras se tejen de enunciaciones anteriores irreductiblemente contingentes, en consecuencia, no es propiamente en el lenguaje donde se constituye el sujeto sino que en las formaciones discursivas que lo determinan socio históricamente, así como determinan su habla.

Mucho se ha escrito en torno al giro lingüístico de la filosofía, aludiendo, entre otras referencias, a la hermenéutica de Gadamer, la pragmática de Rorty, la differance derridiana y también las investigaciones de Foucault, especialmente de Arqueología del saber y El orden del discurso. Jäger, por ejemplo, en el marco de su continuidad crítica con el filósofo francés, sostiene que la noción de formación discursiva está "excesivamente atrapada en lo verbal" y propone considerar el pensamiento como mediación entre lo que 
se dice (discurso), lo que se hace (actividades o prácticas no discursivas) y las manifestaciones (productos y objetos) que resultan de la "activa puesta en práctica del saber" (Jäger 2003:78).

Sin que aceptemos por completo la afirmación de Jäger, por cuanto consideramos que en toda la obra foucaultiana el discurso no es lenguaje sino que una determinante socio histórica de los enunciados que da forma al lenguaje; lo relevante para efectos de nuestro trabajo es observar que el devenir de los estudios del discurso, luego de la impronta de los debates filosóficos y semióticos de la segunda mitad del siglo XX, mantiene su problema fundacional: explicar la constitución social de los enunciados proferidos por los sujetos históricos. La diferencia con el inicio de las investigaciones es que, despejados ahora los presupuestos del autor, el texto y la referencia directa entre los enunciados y el mundo, así como la posibilidad de que los enunciados y el discurso puedan pensarse como un dominio inmanente que cubre todo lo real, la concomitancia entre las palabras y lo que no es reductible a lenguaje requiere ser pensada bajo un movimiento necesariamente transdisciplinario.

Los elementos centrales ya están aludidos en los recorridos anteriores: semiosis, cognición, acción, prácticas, representaciones sociales. Nos limitaremos a indicar algunos elementos centrales de este vasto problema. Como no es esta una historia lineal, al menos dos búsquedas atingentes son contemporáneas a Foucault.

Primero, el rescate de la semiología peirceana, en tanto alternativa para explicar el vínculo más íntimo entre el individuo y lo social, a través de la elección de los signos como procedimiento de base en toda construcción verbal. Según Verón, representamen, objeto e interpretante constituyen tres niveles de abstracción del signo que funcionan relacionando los hechos del mundo en un proceso ilimitado, pero a su vez dependiente de la costumbre (el hábito social), por cuanto las semiosis conocidas marcan las futuras, a través de la pre elección del fundamento o aspecto del objeto que se tomará como interpretante. Estas "ocasiones significantes ya producidas en el pasado" constituyen, entonces "el fundamento último de la realidad y, al mismo tiempo, (...) el fundamento último de la verdad" (Verón 1998:119): es la semiosis social la garantía de la semiosis individual.

Segundo, la vinculación entre enunciación y pragmática. Al respecto, Ducrot sostiene que la escena dialógica de los enunciadores inscrita en el enunciado muestra, a modo de instrucciones implícitas, la fuerza ilocutiva que el enunciado reclama para sí, de esta manera, propone la existencia de una interfaz entre lo que el enunciado dice y lo que el hablante hace al decirlo, así, por ejemplo, "una orden equivale a pretender, por un lado, que el destinatario está obligado a cumplir determinada acción, y, al mismo tiempo, que está obligado a ello como consecuencia de la enunciación que vehicula esa orden" (1984:142); tesis que Fabbri ratifica desde la semiótica, sosteniendo que "un texto lleva inscritas, en forma de sistema enunciativo, las representaciones de cómo quiere ser considerado dicho texto" (2000:85).

El dominio pragmático, en su sentido restringido de teoría de los actos de habla, parece constituir un vértice común en los intentos de explicar las conexiones más elementales entre los enunciados y los sujetos hablantes, sin embargo, parece insuficiente para explicar globalmente la concomitancia de lo social, el discurso y los sujetos; problema que conlleva ampliar la teoría definitivamente hacia el exterior del lenguaje.

La opción de Van Dijk, en tal sentido, es recurrir a la socio cognición para formular una definición de contexto que relacione los elementos en juego, en síntesis, esquema o modelo de carácter mental, formado intersubjetivamente, regular y dinámico, mediante el cual el sujeto interpreta los diversos 
componentes de un evento comunicativo (tipos de conocimiento involucrados, tipo de discurso, temas, estructuras textuales, representaciones sociales, entre otros), dotándolos de significado y adecuación pragmática. Bajo este punto de vista, sostiene, es posible explicar que cada sujeto en cada situación desarrolle significados distintos frente a la multiplicidad de convenciones articuladas y conocimientos compartidos que estructuran un evento, por cuanto "no es la situación social «objetiva» la que influye en el discurso, ni es que el discurso influya directamente en la situación social: es la definición subjetiva realizada por los participantes de la situación comunicativa la que controla esta influencia mutua" (2012:13).

Una alternativa distinta es otorgar a las representaciones sociales el lugar de esa interfaz buscada, concepto que refiere los conocimientos de diverso tipo y generalidad de los que dispone una colectividad en su producción discursiva y que circulan como enunciados. Al respecto, Fairclough sostiene: "Los discursos son diferentes representaciones de la vida social cuya posición se halla intrínsecamente determinada; los actores sociales de distinta posición "ven» y representan la vida social de maneras distintas, con discursos diferentes" (2003:182), su enlace con la subjetividad es formulado aquí a partir de las teorías semiótica y de la acción: en toda práctica, en tanto forma regulada de la acción social, hay un componente semiótico en alguna de sus modalidades, luego, una parte de este dominio suplementario se articula, mediante enunciados verbales, en representaciones de esas prácticas. En consecuencia, "podemos entender la vida social como una serie de redes interconectadas de prácticas sociales de diferentes tipos (económicas, políticas, culturales, etcétera). Y cada práctica tiene un elemento semiótico" (2003:180).

Puede notarse que ambos conceptos, modelos de contexto y representaciones sociales, asumen una función análoga en sus respectivos sistemas conceptuales: conectar el saber social, relativamente regular, con las actualizaciones siempre singulares que caracterizan a todo evento comunicativo. En ese marco, mientras Van Dijk recalca que los esquemas mentales del sujeto, formados intersubjetivamente, son el elemento crucial del problema; bajo el segundo punto de vista lo central son las significaciones socialmente consignadas de lo real, base sobre la cual los nuevos enunciados se articulan.

Tras estas diferencias trasunta una controversia que de una u otra manera marca todos los estudios sobre el lenguaje del siglo XX: el lugar de la cognición en relación con la articulación social de los enunciados. Van Dijk lo llama el problema del mentalismo o la renuencia a aceptar que las estructuras cognitivas del yo individual median entre las estructuras sociales y el discurso, aludiendo con ello a las teorías de raíz marxista y a la obra de Foucault, que desconocen dicha preponderancia y sostienen el carácter principalmente socio histórico y no subjetivo de la significación.

Un conocido diálogo televisado entre Chomsky y Foucault, en 1971, versa en su primera parte sobre este tópico: frente a la pregunta de si existe una naturaleza humana, el lingüista estadounidense afirma que el aprendizaje infantil en todas sus dimensiones no es explicable sin reconocer que existe una cierta forma de "conocimiento instintivo", un "conjunto de esquemas o principios de organización innatos que guían nuestro comportamiento social, intelectual e individual" y este constituye dicha naturaleza (2012:11); frente a ello, Foucault afirma: "la creación o innovación solo existe dentro de un horizonte de lo posible. En términos del lenguaje o del conocimiento, solo es posible producir algo nuevo en el marco de ciertas reglas que definirán la aceptabilidad o la gramaticalidad de los enunciados, o que definirán, en el caso del conocimiento, su carácter científico" (2012:34). 
No son planteamientos necesariamente opuestos y refieren problemáticas fundamentalmente filosóficas, pero su impronta en el devenir del análisis de discurso no es menor. Así, Van Dijk, inscrito en la primera línea (sin por ello asignarle un vínculo más general con Chomsky), sostiene: "si los contextos representaran condiciones o límites sociales objetivos, todas las personas de la misma situación social hablarían de la misma manera. Por lo tanto, la teoría debe evitar el positivismo, el realismo y el determinismo social al mismo tiempo: los contextos son constructos de los participantes" (2012:14). En cambio, para Pêcheux, que adscribe abiertamente a un enfoque de raíz marxista, toda adscripción del sentido de un enunciado al trabajo de un sujeto autónomo es un efecto ideológico idealista que, en el plano de la teoría, se expresa en los sistemas de Saussure, del mismo Chomsky o de Benveniste; así, la investigación lingüística centrada en describir las marcas del sujeto enunciador en el enunciado y toda la teoría que concibe el lenguaje como mediación del sujeto y el mundo, por más que integre lo ideológico en cuanto plano del análisis (como en el caso del propio Van Dijk), es criticada globalmente, para postular, en cambio, la determinación sociohistórica, no subjetiva, del habla.

Este debate muestra que las conexiones más amplias y complejas de los sujetos históricos con sus enunciados no pueden ser explicadas en términos semióticos, pragmáticos o cognitivos; es necesaria una reflexión referente a los modos estructurales de esa imbricación, donde los conceptos de ideología y poder -puede ya inferirse- asumen un lugar central e ineludible.

\section{Ideología y poder}

En términos generales, existen algunas convenciones al respecto de ambos conceptos: las prácticas discursivas son afectadas por el poder diferencial de instituciones y sujetos, muestran huellas ideológicas de sus condiciones de producción y ejercen poder de modos variados; no obstante, las distintas definiciones de los términos, así como sus concatenaciones con el lenguaje, muestran diferencias significativas; controversias que expresan debates filosóficos más amplios que alcanzan incluso la validez del propio concepto de ideología, de acuerdo al decurso del llamado marxismo occidental y sus debates con el posestructuralismo.

Un antecedente significativo de las controversias posteriores en este ámbito es la obra clásica de Volóshinov El marxismo y la filosofía del lenguaje que, en 1929, define lo ideológico como la refracción de los fenómenos sociales en signos, de modo tal que el lenguaje es concebido como un dominio suplementario de la ideología y no se explica fuera de ella, siendo la conciencia individual (como en Pêcheux) un mero efecto distorsionado de esta realidad: "La realidad de los fenómenos ideológicos es la realidad objetiva de los signos sociales. Las leyes de la realidad son leyes de la comunicación semiótica determinadas directamente por todo el conjunto de las leyes económicas y sociales. La realidad ideológica es una superestructura inmediata que surge sobre la base económica. La conciencia individual no es el arquitecto de la superestructura ideológica, sino tan solo un inquilino alojado en el edificio social de los signos ideológicos" (Volóshinov 2009:32).

La fundación de los estudios sobre el discurso, sin embargo, está marcada no solo por los enfoques de raíz marxista, sino que por la obra de Foucault, quien sostiene tesis distintas. Primero, cuestionando la validez teórica del concepto de ideología, al considerar que este siempre se ubica "en oposición virtual a algo que sería la verdad", implica necesariamente un sujeto y "está en posición secundaria respecto a algo que debe funcionar para ella como infraestructura o determinante económico, material, etc." (1992:192). Segundo, manteniendo que los discursos no resultan de la conexión entre una realidad exterior y el lenguaje, sino que constituyen "prácticas que forman sistemáticamente los objetos de los que hablan" (2003:81). Y, 
tercero, elaborando una noción de poder que no refiere fundamentalmente al efecto de las instituciones del aparato estatal -en el sentido de las tesis de Althusser- sino que a cualquier "manera de actuar sobre un sujeto actuante o sobre sujetos actuantes, en tanto que actúan o son susceptibles de actuar. Un conjunto de acciones sobre otras acciones" (1988:239), recubriendo entonces todo el dominio entre la incitación y la prohibición que se ejerce mediante instituciones, prácticas y, también, enunciados.

Frente a estos horizontes conceptuales, el devenir del análisis de discurso no ha optado por el posicionamiento estricto, las diferencias hay que observarlas sobre el trasfondo que forman en su conjunto, sin desmedro de la impronta de otras tradiciones que exceden los límites de este trabajo, como la hermenéutica o la Escuela de Frankfurt.

El ejemplo más claro de un intento por elaborar una teoría sobre el discurso a partir de la conexión entre fuentes marxistas y la herencia foucaultiana, es la obra de Pêcheux. Para este autor, la noción de formación discursiva "pertenece" a lo que llama formación ideológica o "conjunto complejo de actitudes y de representaciones que no son ni «individuales» ni "universales», pero que se refieren más o menos directamente a posiciones de clases en conflicto las unas con relación a las otras" (1978:233), de modo que siempre varias formaciones discursivas constituyen uno de los "aspectos materiales" de las formaciones ideológicas, determinando lo que puede y debe ser dicho.

Esta irreductibilidad del discurso al conflicto de clases es la sustentación del modelo de análisis -ya comentado- que propone Pêcheux: las relaciones parafrásticas que determinan el sentido de todo enunciado individual son expresión de las formaciones ideológicas en que se inscribe, de ahí su carácter no subjetivo. Una paradoja resulta de esta tesis, que el propio Pêcheux considera el núcleo problemático de la definición de discurso: el sentido como el sujeto no preceden a la ideología y, sin embargo, solo se manifiestan como efectos para sujetos cuya evidencia es ser anteriores a la ideología.

Eliseo Verón, en La Semiosis Social, sostiene un alcance distinto de la ideología, a la vez que tematiza el poder. A partir del esquema triádico de Peirce (comentado en el punto anterior), afirma que el sentido, en cuanto remisión ilimitada de los signos fundamentada en la costumbre, lo ideológico constituye el "sistema de relaciones de un discurso (o de un tipo de discurso) con sus condiciones de producción, cuando éstas ponen en juego mecanismos de base del funcionamiento de una sociedad" y el poder, el "sistema de relaciones de un discurso con sus efectos, cuando las condiciones de reconocimiento conciernen a los mecanismos de base de funcionamiento de una sociedad" (Verón 1998:134).

Ambas definiciones refieren explícitamente a "reglas" o "gramáticas discursivas" (1998:135) de producción o recepción y no a las ideologías históricamente configuradas ni al ejercicio del poder a través de las instituciones del aparato estatal, es un uso de los conceptos que busca delimitar lo propiamente discursivo y no exige explicar mediante la remisión a los conflictos de clase toda la complejidad de las secuencias verbales: lo ideológico y el poder son dominios inherentes al discurso, pero este no es reductible a ambos.

Un enfoque todavía más general es el formulado por Van Dijk: la ideología constituye un conjunto de "representaciones sociales compartidas por los miembros de un grupo" (2006:21) que afectan las creencias y evaluaciones de base que los constituyen como tal, regulando tanto la interpretación global de la diferencia social como las prácticas cotidianas en que opera esa diferencia y pueden estructurarse en torno a la dominación, la resistencia, la competencia o la cohesión. 
La ideología, desde este punto de vista, es fundamentalmente un esquema de "unidades de información y de procesamiento de la información" (Van Dijk 2006:38), que actúan al mismo tiempo como "condiciones y consecuencias" (Van Dijk 2006:45) del discurso y de otras prácticas sociales y culturales, carácter que supone negar que el sujeto y el discurso constituyan dominios determinados por la ideología y remite a la noción de poder, por cuanto su carácter de modelo contextual de base le permite formar marcos cognitivos que controlan las prácticas de comunicación, básicamente según tres modos: determinando derechos de acceso al discurso, regulando la interacción discursiva e inscribiendo marcas ideológicas en los diversos planos que componen el texto, orientando de ese modo la interpretación: superestructuras, macro estructuras, conexiones y, en general, significados explícitos e implícitos que acentúan u omiten informaciones, "sugiriéndose así fuertemente que tal información se considera incontrovertida o dada por sentado, aunque en realidad no lo sea o no lo esté" (Van Dijk 2009:169).

De un modo general, las alternativas principales ya están dispuestas en estos tres autores, otros enfoques reorganizan los mismos lineamientos y, en algunos casos, ingresan nuevas categorías.

Jäger, por ejemplo, al integrar el enfoque foucaultiano con teorías sobre la cognición social y, con ello, inscribiendo el sujeto en las formaciones discursivas, afirma que es en el fluir del conocimiento social, constitutivo del discurso, donde se determinan "los hechos individuales o colectivos, así como la acción formativa que moldea la sociedad y que, de este modo, ejerce el poder" (2003:63), marco en el cual lo ideológico no constituye una visión distorsionada o falsa de la realidad social sino que un plano más general y fundante: en tanto todo conocimiento está vinculado al poder y se expresa en discursos hegemónicos y contra hegemónicos, lo ideológico es el trasfondo, también discursivo, de ese conflicto, que "crea las condiciones para la formación de sujetos y la estructuración y configuración de las sociedades" (2003:65).

En un sentido más restringido del término, Fairclough afirma que un orden del discurso es "una estructuración social de la diferencia semiótica" (2003:183), que se instituye como red de diferencias posibles que regula la producción discursiva, contexto en el cual se instituyen formas hegemónicas, contra hegemónicas, marginales y alternativas que disputan el "sentido común" de la sociedad; lucha que da forma al discurso ideológico, definido como aquel "que contribuye a mantener unas particulares relaciones de poder y de dominación" (2003:187).

No obstante, Fairclough aborda -tal como Pêcheux- el contexto histórico más amplio en que se forman las redes discursivas, proponiendo que lo ideológico debe ser observado no solo como dominio conceptual abstracto sino que en cuanto manifestación singular de una sociedad determinada: el orden discursivo es la dimensión semiótica de un orden social, entendido como la red general de prácticas entre las cuales actúa lo verbal y que incluye todos los aspectos económicos, culturales e históricos que definen a una sociedad, de esta manera, pensar las prácticas discursivas del presente en los estados occidentales implica considerar el capitalismo neoliberal como trasfondo. Fairclough lo ejemplifica con el concepto de economía basada en el conocimiento, huella de un orden económico caracterizado, entre otros elementos, por prácticas discursivas que ubican los textos en regímenes de circulación y consumo específicos. Desde esta perspectiva: "La reestructuración y la asignación de una nueva escala al capitalismo es en parte un proceso semiótico -el de la reestructuración y la asignación de una nueva escala a los órdenes del discurso, lo que implica unas nuevas relaciones estructurales y escalares entre las variedades discursivas, los discursos y los estilos" (Fairclough 2003:188). 
Las diferencias entre estos modelos muestran tres ejes de alternativas en torno a la ideología que, sostenemos, se mantienen en una revisión más amplia del campo disciplinario, que no es posible realizar aquí.

Primero, el eje de la generalidad, donde es posible comprender lo ideológico ya sea como dominio que recubre y explica la totalidad de lo discursivo o como plano, entre otros, que alude a la inscripción de los textos en la estructura social, sin agotar los fenómenos rastreables en el enunciado.

Segundo, el asunto de la definición o dependencia de lo ideológico, ya sea como expresión de los conflictos de clase, manifestación de los aspectos definitorios de la estructura social (entre ellos, la diferencia de clase) o efecto de la diferencia y el conflicto bajo los cuales se definen los grupos de una sociedad y de una sociedad en relación con otras.

En tercer lugar, el problema de su concomitancia con el sujeto y el discurso: ideología en cuanto dominio en que se forman el sujeto y el sentido; como efecto de los procesos sociales de base en que se forman los discursos producidos por los sujetos que, por ende, no constituyen como tales figuras completamente ideológicas; o en tanto conjunto de creencias de base (pre discursivas) de los sujetos, dependientes de los grupos sociales y las sociedades a las que pertenecen, de donde la ideología es un plano entre otros de las estructuras cognitivas de los sujetos.

Por último, es la ideología un concepto que describe un cierto dominio de fenómenos propios de cualquier sociedad y época, o bien constituye una manifestación de las contradicciones de las sociedades capitalistas que puede adquirir -presumiblemente-formas muy distintas en otras formaciones sociales.

En cambio, pensar el poder en su relación con la ideología y el discurso parece plantear menos inconvenientes: en todos los acercamientos se acepta que los discursos están cruzados por las diferencias de poder de los sujetos que los hacen circular, fundamentalmente a través de los tres ejes mencionados por Van Dijk: acceso, interlocución, representación.

De este modo, la noción foucaultiana del poder como microfísica ha podido integrarse con su uso como manifestación de la reproducción de las condiciones sociales de producción, que ejercen los aparatos ideológicos del Estado, posiblemente como resultado de que cada corpus de investigación puede ser observado desde ambas perspectivas.

\section{Conclusión}

Los debates que han marcado la historia de los estudios del discurso conciernen de modo relevante a las interconexiones entre espacios interiores y exteriores al lenguaje: más allá de los análisis efectuados, lo atestiguan la crítica de Jäger a Foucault por no explicar satisfactoriamente "la mediación entre el sujeto y el objeto, ni la sociedad y el discurso como elementos que resultan del trabajo, la actividad y las prácticas no discursivas" (2003:76); de Van Dijk a los enfoques foucaultianos al afirmar la insuficiencia de la noción de práctica para explicar "la naturaleza de las relaciones entre la sociedad y el discurso" (2012:49); de Maingueneau al análisis crítico de discurso al advertir que si el núcleo del análisis lo constituyen las representaciones sociales, "se corre el riesgo de hacer insípido, de disolver el AD" (2000:70). Y, sin embargo, ya en los inicios de esta, Verón polemizaba con Pêcheux por su intento de rastrear contenidos puramente lingüísticos como etapa primera del análisis discursivo intertextual, al tiempo que ambos 
concordaban en cuestionar la noción de situación de enunciación de Benveniste y, en cambio, defender el carácter social e intertextual de la enunciación.

Sostenemos que esta difuminación de su concepto es el trasfondo en que se han configurado los modelos: la determinación del dominio de lo discursivo en relación a los planos del lenguaje y lo social.

Aunque tal complejidad es inherente a todo campo de estudios, nos parece aquí más acentuada que, por ejemplo, para el caso de la lingüística, la semiótica o la pragmática, toda vez que los debates en tales disciplinas problematizan ciertas nociones de base (a saber, lengua, signo, acto de habla) que alguna vez parecieron estables. El análisis de discurso, en cambio, nace bajo la pregunta por un entre que nunca se ha dejado asir y cuya indagación ha resultado en la determinación de objetos heterogéneos, básicamente, enunciados contextualizados, prácticas verbales de composición de enunciados o sistematicidades sociohistóricas de composición de enunciados, en definitiva, el contexto inscrito en los enunciados o las reglas de formulación de los enunciados: la diferencia principal aquí no es la extensión de lo discursivo sino que su materia o su objeto, así, extremando las diferencias, el analista observará un conjunto de enunciados que se asumen explicativos de sus condiciones de producción o un conjunto de prácticas, modos de enunciación, enunciados y sujetos, en su sistematicidad.

A ello se suma la disparidad de la inscripción del concepto en coordenadas más amplias, como efecto del devenir propio de los concomitantes del enunciado: sostener, por ejemplo, el discurso como dominio interior a la ideología, uno de cuyos efectos es la figura del sujeto, o como representación de lo social determinada por esquemas cognitivos pre discursivos, constituyen dos marcos significativamente distintos del concepto, que le otorgan alcances muy diversos al interior de las ciencias abocadas a comprender lo social; en esto, claramente, el análisis de discurso se muestra dependiente de controversias de mayor amplitud.

Desde esta perspectiva, no parece posible efectuar un análisis de discurso al interior de una investigación o como método general de la misma sin asumir opciones epistémicas sustantivas, que no pueden solucionarse bajo el recurso de afirmar su carácter transdisciplinario o sosteniendo simplemente que la pregunta, el objeto o el corpus orientan las decisiones de método.

Precisamente, el asunto es que la noción de discurso utilizada, incluso si el investigador no lo percibe, permitirá o impedirá ciertas preguntas, desplazará las fronteras del objeto y el corpus, el ámbito de las observaciones posibles en su interior. En definitiva, frente a conjuntos de enunciados que dicen y ocultan un sentido, ¿qué decisiones tomaremos?, por ejemplo:

(a) Adoptaremos como unidades relativas de sentido las manifestaciones de esos enunciados en estructuras textuales o nos orientaremos a las conexiones entre enunciados que atraviesan los textos. Obsérvese que, entre otras implicaciones, esta opción supone integrar o excluir un conjunto vasto de categorías lingüísticas y enunciativas que permiten observar la "escena" del discurso en cuanto texto.

(b) Asumiremos que lo discursivo atañe al dominio de lo verbal y que solo en ese marco son necesarias conexiones con aquello que se defina como contexto extra lingüístico, u optaremos por afirmar que el sentido no es reductible a la semiosis verbal, sino que se instituye necesariamente como efecto de la conexión entre planos heterogéneos. 
(c) Decidiremos que lo discursivo se resuelve en remisiones entre enunciados presentes u ocultos y entre estos y sus referentes, o afirmaremos la existencia de planos subjetivos pre discursivos que explican la formación de los enunciados, en conexión con los referentes.

(d) Optaremos por afirmar que lo discursivo es el plano al interior del cual se forman las representaciones ideológicas o sostendremos que las ideologías, dependientes ya sea de estructuras socio históricas generales o específicamente de las diferencias de clase, explican y recubren todo el plano de las manifestaciones discursivas.

Cada opción forma preguntas, objetos y corpus distintos. Por tal razón, es necesario observar con cautela cualquier propuesta metodológica de análisis de discurso. Por ejemplo, Santander plantea, luego de una revisión de las complejidades del campo: "Si bien no existe un modelo único de análisis, sí se puede afirmar que toda investigación que contemple el análisis discursivo y que quiera enfrentarse exitosamente a la interpretación sígnica, debe mostrar siempre una coherencia rigurosa entre categorías conceptuales, categorías discursivas, categorías lingüísticas/semióticas y recursos gramaticales de base" (2011:217).

Aseveración que en ningún caso consideramos errónea o discutible, afirmamos que ya ha tomado las decisiones fundamentales, entre otras: el discurso se manifiesta en textos, su sentido es rastreable gramaticalmente y la ideología constituye solo una entre otras "categorías conceptuales" de contexto.

Por último, la cautela metodológica supone controlar la integración de autores que respondan a enfoques distintos. Por ejemplo, si la investigación observa prácticas de poder representadas en textos, utilizar como fuentes las investigaciones de Foucault y Van Dijk puede resultar problemático: Van Dijk escudriña la trama verbal de los enunciados y busca explicaciones socio cognitivas e ideológicas de sus representaciones, Foucault inscribe cualquier fragmento textual en contingencias históricas, no en la búsqueda de representaciones o ideologías pre discursivas ni de estructuras de lenguaje, sino que de reglas de conexión y separación de ese enunciado con otros, con prácticas, posiciones de sujeto y contingencias, que constituyan huellas de dispositivos de saber-poder.

En el contexto de un creciente interés por el análisis de discurso en las humanidades y las ciencias sociales, estas líneas proponen a los investigadores no especialistas una mirada atenta de los modelos teóricos que sustentan las estrategias de análisis. De lo contrario, los resultados pueden adolecer de importantes inconsistencias u ocultar importantes presupuestos epistémicos.

\section{Bibliografía}

Adam, J-M. y Heidmann, U. 2004. Des genres à la généricité. L'exemple des contes (Perrault et les Grimm). Langages 38(153): 62-72.

Bajtín, M. 2008. Estética de la creación verbal. Buenos Aires: Siglo XXI.

Benveniste, E. 2011. Problemas de lingüística general I. México: Siglo XXI.

Charaudeau, P. 2004. La problemática de los géneros. De la situación a la construcción textual. Revista Signos 37(56): 23-39. doi: 10.4067/S0718-09342004005600003

Ducrot, O. 1984. El decir y lo dicho. Buenos Aires: Hachette.

Fabbri, P. 2000. El giro semiótico. Las concepciones del signo a lo largo de la historia. Barcelona: Gedisa. 
Fairclough, N. 2003. El análisis crítico del discurso como método para la investigación en ciencias sociales. En: R. Wodak y M. Meyer. Métodos de análisis crítico del discurso. Barcelona: Gedisa, pp. 179203.

Filinich, M. I. 2012. Enunciación. Buenos Aires: Eudeba.

Foucault, M. 2012. El orden del discurso. Buenos Aires: Tusquets

Foucault, M. 2003. La arqueología del saber. México: Siglo XXI.

Foucault, M. 1992. Microfísica del poder. Madrid: La Piqueta.

Foucault, M. 1988. El sujeto y el poder. En: H. Dreyfus y P. Rabinow. Michel Foucault: más allá del estructuralismo y la hermenéutica. México: Universidad Nacional Autónoma de México, pp. 227-240.

Heidegger, M. 2005. Ser y tiempo. Santiago: Universitaria.

Jäger, S. 2003. Discurso y conocimiento: aspectos teóricos y metodológicos de la crítica del discurso y del análisis de dispositivos. En: R. Wodak \& M. Meyer. Métodos de análisis crítico del discurso. Barcelona: Gedisa, pp. 61-100.

Kerbrat-Orecchioni, C. 1997. La enunciación. De la subjetividad en el lenguaje. Buenos Aires: Edicial. Maingueneau, D. 2000. Peut-on assigner des limites à l'analyse du discours? Modeles Linguistiques 20(2): 61-70.

Maingueneau, D. 2009. Análisis de textos de comunicación. Buenos Aires: Nueva Visión.

Pêcheux, M. 1978. Hacia el análisis automático del discurso. Madrid: Gredos.

Santander, P. 2011. Por qué y cómo hacer análisis de discurso. Cinta de Moebio 41: 207-224. doi: 10.4067/S0717-554X2011000200006

Saussure, F. D. 1991. Curso de lingüística general. Madrid: Akal.

Van Dijk, T. 2012. Discurso y contexto. Barcelona: Gedisa.

Van Dijk, T. 2009. Discurso y poder. Contribuciones a los estudios críticos del discurso. Barcelona: Gedisa.

Van Dijk, T. 2006. Ideología. Una aproximación multidisciplinaria. Barcelona: Gedisa.

Van Dijk, T. 1983. La ciencia del texto. Barcelona: Paidós.

Verón, E. 1998. La semiosis social. Fragmentos para una teoría de la discursividad. Barcelona: Gedisa.

Volóshinov, V. 2009. El marxismo y la filosofía del lenguaje. Buenos Aires: Godot.

Recibido el 31 Mar 2015

Aceptado el 24 Jun 2015 